\title{
The Role of Self-Reflection in an Indigenous Education Course for Teacher Candidates
}

\author{
Melissa Oskineegish \\ Lakehead University \\ Author's Note
} Canada.

This research was supported by the Social Sciences and Humanities Research Council of

The author can be contacted through email at mmoberly@lakeheadu.ca

\begin{abstract}
This paper explores the role of self-reflection in a teacher education program. In a mandatory Aboriginal Education course in northwestern Ontario, teacher candidates participated in a variety of self-reflection activities that included two reflection papers, non-traditional sharing circles, and lectures, and classroom discussions that challenged common myths, stereotypes, and prejudices about Indigenous peoples. In a survey with open-ended questions administered at the end of the course, 36 teacher candidates shared their perspectives about self-reflection at the end of the course. Findings from the survey were correlated with seven teacher candidates' reflection papers and with my personal reflections as a participant-as-observer in two of the mandatory courses. The themes that emerged from analysis were placed into three categories; these categories described the role of self-reflection as a process of (1) self-evaluation, (2) establishing personal connections with course theory, and, (3) developing a culturally inclusive pedagogy. The findings suggest that self-reflection in an Indigenous Education course can provide teacher candidates with an effective approach to uncover, identify, and examine internal biases that impact their understanding of teaching Indigenous students and integrating Indigenous content into the curriculum.
\end{abstract}

Keywords: Indigenous Education; self-reflection; teacher education

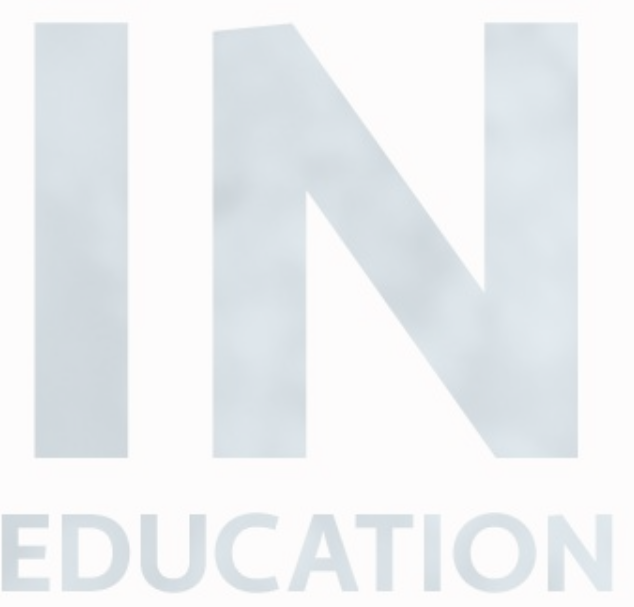




\section{The Role of Self-Reflection in an Indigenous Education Course for Teacher Candidates}

Self-reflection in education is recognized as a valuable method for developing and improving teachers' professional practice (Farrell, 2012; Mason, 2007; Milner, 2003; Ottesen, 2007; Rodgers, 2002; Schön, 1983). In teacher preparation, self-reflection and reflective practices are utilized for eliciting and examining teacher candidates' personal beliefs and theories about teaching, learning, and the curriculum (Stock, Sameshima, \& Slingerland, 2016; Tann, 1993; White, Sameshima \& Sinner, 2015). Advocates of culturally responsive teaching refer to selfreflection as a process for developing self-awareness and understanding of one's own cultural frames of reference (Gay, 2010; Hammond, 2015; Villegas, 1988). In Hammond's (2015) work on culturally responsive teaching, she encouraged teachers to engage in self-reflection and reflective activity to "examine the deeply held beliefs that influence how they respond to students" (p. 56). Self-examination through reflection is described as vital in cross-cultural teaching contexts as teachers are asked to become cognizant of their biases and reactions to students and curriculum (Delpit, 2006; Grant \& Sleeter, 2007; Nuri-Robins, Lindsey, Lindsey, \& Terrell, 2012). The findings in this paper explore teacher candidates' perspectives on the role of self-reflection in a mandatory Aboriginal Education course in a teacher education program. Focusing on self-reflection has the potential benefit of improving teacher candidates' capacity to value and engage with knowledge and perspectives different than their own by increasing their self-awareness in relation to Indigenous content in teacher education courses.

\section{Context}

Researchers across Canada have described various ways that teacher candidates can increase their knowledge and understanding to integrate Indigenous histories, cultures, and perspectives into their teaching practice (Nardozi, Restoule, Broad, Steele, \& James, 2014; Scully, 2012; Tupper, 2011; Vetter \& Blimkie, 2011). The most common observation from the analysis of relevant teacher education research was teacher candidates' overwhelming lack of knowledge and understanding of Indigenous knowledge and issues in education (Blimkie, Vetter, \& HaigBrown, 2014; Nardozi et al., 2014) as well as a lack of awareness of the historical and current relationship between Indigenous and non-Indigenous peoples in Canada (Dion, 2007; Tupper, 2011). Added to this, was a persistent resistance by some teacher candidates to learn about, or value the integration of Indigenous histories, cultures, and perspectives, with mandated Kindergarten to Grade 12 curriculum (Mashford-Pringle \& Nardozi, 2013).

Teacher candidates arrived in teacher education programs with theories, ideas, and beliefs about education and schooling that derived from personal experiences (Keltchermans, 2009; Tann, 1993). Because of the large number of teacher candidates with inaccurate, little, or no knowledge of the cultural heritage of Indigenous peoples in Canada, it is important that teacher candidates examine their own beliefs, assumptions, and biases that shape and influence their pedagogical practices. In the study presented here, self-reflection was examined as a potential approach for teacher candidates to uncover internal biases and to develop their understanding of teaching Indigenous learners and integrating Indigenous content.

\section{Literature Review}

The theoretical framework of this study was guided by literature on culturally responsive teaching (Gay, 2010; Hammond, 2015). The term culturally responsive teaching has numerous variations such as culturally responsive pedagogy (Ladson-Billings, 1994), culturally responsive 
schooling (Castagno \& Brayboy, 2008), and culture-based education (Demmert Jr., 2011). The main focus of the study described in this paper was the preparation of teachers to teach Indigenous students in a culturally responsive framework. That being the case, the term culturally responsive teaching and acronym CRT is used throughout this review to represent the variations within this body of work.

The purpose of CRT is to eliminate cultural incongruence and increase the academic achievement of students by providing an education that is both "validating and affirming" (Gay, 2010, p. 31) to all students. A CRT approach to teaching does not view cultural differences as a disadvantage; instead it advocates for students' cultural backgrounds to be a source for pedagogical knowledge and content (Castagno \& Brayboy, 2008; Hammond, 2015; Villegas \& Lucas, 2002). In Hammond's (2015) connection of CRT with neuroscience, she wrote that culture is the way in which every brain makes sense of the world, and that for anyone to learn, "all new information must be coupled with existing funds of knowledge" (p. 48). In other words, "all learners have to connect new content to what they already know" and what students "already know is organized according to ... cultural experiences, values, and concepts" (p. 49). This approach is often advocated for in Indigenous schools or communities (Oskineegish, 2015).

Developing a CRT approach to education in an Indigenous context often requires three tasks or components that an educator must engage in. I have described the first component as the acquisition of accurate knowledge within Indigenous education (Castagno \& Brayboy, 2008; Lewthwaite, Owen, Doiron, McMillan, \& Renaud, 2013; Villegas \& Lucas, 2002). This foundational knowledge includes an understanding of the historical and current relationships between Indigenous and non-Indigenous people and communities in Canada (Cannon, 2012; Dion, 2007, 2009), and the impact of political, social, and educational policies and practices that have affected Indigenous peoples throughout Canada, such as the Canadian Indian Residential School system (Miller 2003; Regan, 2010; TRC, 2012). The second component is described as knowledge that emerges from reciprocal relationships between teachers and students, families, and local Indigenous communities (Moll, Amanti, Neff, \& Gonzalez, 1992). A teacher's capacity to develop caring relationships with students in the classroom has a direct impact on students' comfort, well-being, and academic achievement (Cohen \& Bai, 2012). In CRT, the relationships between a teacher and students, parents, and community members forms the foundation for understanding who a student is, and that exposes a teacher to specific experiences and knowledge that can be drawn upon in lesson development (Oskineegish \& Berger, 2013; Villegas \& Lucas, 2002). It is relationships with people, not objects, that are the root of understanding culture (Curwen Doige, 2003). The third component, and the focus of this paper, is the necessity of self-awareness and self-knowledge as it relates to teacher development (Gay, 2010; Hammond, 2015). Self-awareness is described as the act or willingness to reflect critically on one's own beliefs and attitudes (Garmon, 2004). Self-awareness brings forward the potential for teachers to see how their experiences have shaped their knowledge, beliefs, and attitudes, and how this understanding informs their teaching approach (Sameshima, 2007). In CRT, selfawareness is also the willingness to reflect critically on experiences that have informed one's own concepts of race and racism, White privilege, and oppression (Solomon, Portelli, Daniel, \& Campbell, 2005). In this paper, the use of a self-reflective paper is reviewed as an approach for promoting self-awareness and self knowledge in a mandatory Aboriginal Education course in a teacher education program. 


\section{Self-Reflection}

Scholars who have investigated teacher preparation in cross-cultural teaching have identified self-reflective practices as a way in which to open teacher candidates to new and alternative ways of teaching and learning (Gay \& Kirkland, 2003; McDowall, 2017). In Tann's (1993) description of the role of self-reflection in teacher preparation, she wrote that teacher candidates arrive in teacher education programs with prior experiences, knowledge, beliefs, and assumptions which she identified as their "personal theory." She explained that teacher candidates must "elicit and articulate their personal theories ... [to access] their ways of conceptualizing teaching, learning, and the curriculum" (p. 56), arguing that self-reflective practice is an effective process that expands and clarifies teacher candidates' personal beliefs, ideas, and assumptions through "the challenge of comparison and contrast" (p. 56). This process leads teacher candidates to open themselves to new ways of thinking about teaching that extend beyond their own experiences. Part of the purpose of Indigenous content in teacher education programs is to eliminate the concept of deficiency when discussing cultural difference, and to foster an understanding and awareness that colonialism and racism is everyone's problem, not just an Indigenous struggle (Cannon, 2012; Schick \& St. Denis, 2005). This is accomplished not by only learning about others, but by learning about one's self, one's own beliefs and attitudes, and how these have been shaped by one's social, cultural, and political experiences (Nuri-Robins et al., 2012).

One of the challenges of implementing self-reflection is an overall lack of clarity surrounding its purpose and use in teacher preparation and development (Ottesen, 2007; Rodgers, 2002; Russell, 2013; Valli, 1993). As Russell (2013) explained: "Teacher candidates tend to complete a program with a muddled and negative view of what reflection is and how it might contribute to their professional learning" (p. 87). These challenges may be exacerbated in Indigenous education courses that prepare large numbers of non-Indigenous teachers who possess little to no prior knowledge or understanding of Indigenous education issues or perspectives (Nardozi et al., 2014).

In previous research focused on Indigenous education courses in Faculties of Education, there are only a few examples of the use of self-reflection activities (e.g., Aveling, 2006; Dion, 2007; Iseke-Barnes, 2008; McInnes, 2017; Scully, 2012; Wolf 2012), and none that have focused specifically on students' perspectives of self-reflection on their developing understanding of teaching Indigenous students. In this study, teacher candidates responded to two open-ended questions at the end of the course about the role of self-reflection in the course after completing a self-reflection paper, and in-class discussions and sharing circles that invited teacher candidates to engage in self-reflection. They described the various ways that self-reflection assisted in uncovering internal biases and assumptions, as well as the challenges encountered with selfreflection in a teacher education course. The findings suggest that self-reflection in an Indigenous education course is an effective method for confronting biases, which more often than not encourages teacher candidates to be more open to developing an understanding of integrating Indigenous content and inclusive pedagogical practices.

\section{Methodology}

The findings in this paper are drawn from a mixed methods study that embedded a smaller quantitative approach within the larger qualitative research design (Creswell, 2010; Johnson, 
Onwuegbuzie, \& Turner, 2007; Tashakkori \& Teddlie, 2010). The combination of methods was built on a complementary stance as each paradigm was kept separate in its administration and analysis (Creswell, 2010). Data collection for the broader research derived from multiple methods (i.e., an 11 item 5-point Likert survey, three open-ended questions, semi-structured interviews, student artifacts, and reflective journaling) and from multiple perspectives (i.e., teacher candidates from two sections of Aboriginal Education, current and previous Aboriginal Education instructors, and my role as participant-as-observer).

In this paper, the written responses from two of the open-ended questions are examined with eight reflection papers completed by teacher candidates enrolled in two sections of an Aboriginal Education course, and journal entries of my personal thoughts, reactions, and ideas during my participant-as-observer role in both sections of the Aboriginal Education course (DeWalt \& DeWalt, 2002; Savin-Baden \& Major, 2013). The position of participant-as-observer helped me, as a non-Indigenous researcher, to understand what I read in the literature, and occasionally helped directly in my understanding of the role of self-reflection as described by teacher candidates in the study.

The teacher candidates $(n=44)$ who participated in this study completed a mandatory Aboriginal Education course in the fall 2016 semester of a teacher education program. Through participation and classroom conversations, it was evident that nearly all teacher candidates in both courses were non-Indigenous. Twenty-three teacher candidates were undergraduate students in the concurrent education program, completing the Aboriginal Education course in 12 weeks. Twenty-two teacher candidates were in the 1-year teacher education program, completing the course in nine weeks. Both courses were taught by Dr. Paul Cormier, an Indigenous instructor who followed a similar course design and instructional strategy in each course.

Dr. Cormier, who is Anishinaabe from Red Rock Indian Band, utilized a variety of assignments and methods of instruction that promoted self-reflection. These included: a) two personal reflection papers (approximately three pages in length) that asked teacher candidates to synthesize their understanding of required class readings with a personal examination of their perspective or position towards Indigenous education; b) non-traditional sharing circles that provided teacher candidates with knowledge of the ceremonial teachings of a traditional sharing circle by the instructor (Lavallee, 2009; Nabigon, Hagey, Webster, \& Mackay, 1999) and, during which teacher candidates shared their personal experiences and thoughts on course readings or assignments; and, c) lessons that challenged common myths, stereotypes, and assumptions about Indigenous and non-Indigenous historical and contemporary relationships in Canada. He did this by integrating theory, personal stories, experiential learning, and land-based lessons.

On the last day of class, teacher candidates provided feedback on a post-course survey, developed by the researcher, with two open-ended questions that asked: Did you find that the reflection papers supported your learning in this class? Why or why not? And, why do you think teacher candidates are asked to think about their own personal perspectives and understanding of First Nation, Métis, and Inuit histories, cultures, and perspectives in their preparation as a teacher? These questions were finalized prior to the end of the course, and were guided by the pedagogy and content of the course. The decision to focus on teacher candidates' perspectives of the reflection paper occurred for two reasons: First, after the instructor of the course graded the self-reflection papers, he described them as insightful and suggested that I gain teacher candidates' permission to include in the study, and secondly, in my role as participant-as- 
observer, I found that a lot of time throughout the courses were devoted to discussions about the papers. For example, during a non-traditional sharing circle the majority of teacher candidates spoke about what they had written in their reflection paper and how it impacted their understanding of course content

Thirty-six out of a possible 45 teacher candidates from both sections of the course responded to the open-ended questions. Three teacher candidates did not provide a response, and six were absent during the survey administration. All teacher candidates were also invited to share their completed reflection papers with the researcher for use in the study. Seven teacher candidates shared their first reflection paper with me after it was graded and returned. Although I didn't request it, one teacher candidate shared another reflection paper completed at the end of the course for a total of eight papers. To protect participant anonymity, participant codes were assigned for teacher candidates' survey responses and reflection papers during analysis. Each survey was assigned the code, TC, followed by a number, and each reflection paper was assigned a separate code, RP, followed by a number. These codes are used in this paper.

\section{Analysis}

Analysis of the open-ended questions, teacher candidates' reflection papers, and notes from class discussions that emerged from my role as participant-as-observer were conducted using ATLAS.ti, a qualitative coding program. Teacher candidates' responses from the open-ended questions and reflection papers were coded for themes, terms, phrases, and patterns that were repeatedly identified (Creswell, 2010; Savin-Baden \& Major, 2013). From these codes, I developed three categories that captured teacher candidates' perspective of the role of selfreflection in an Indigenous education course, they are: 1) A process for self-evaluation of knowledge, biases, and assumptions about Indigenous cultures, histories, or perspectives acquired either by prior schooling or personal experiences; 2) A process for creating personal connections between personal experiences or beliefs and course theory and reading assignments; And 3) a process for developing a culturally inclusive pedagogy.

From the open-ended questions, 12 teacher candidates provided a response that corresponded to only one of these bulleted points, while 24 teacher candidates described multiple uses for self-reflection that corresponded with more than one. In the self-reflection papers, all eight papers demonstrated evidence of self-evaluation and a connection between personal experiences or beliefs and course theory. Only three of the reflection papers referenced culturally inclusive pedagogy.

The findings within the study provide insight into the multiple uses and, in part, the impact of self-reflection in an Indigenous education course described by teacher candidates. The findings discuss teacher candidates' perspectives of self-reflection in an Indigenous education course.

\section{Findings}

Findings originate from three different analyses: the survey in which $80 \%$ of teacher candidates participated; reflection papers by $15.5 \%$ of teacher candidates in the class; and personal notes from my role as participant-as-observer in 21 classes. On the last day of class, teacher candidates were asked to respond to the following open-ended questions: Did you find that the reflection papers supported your learning in this class? Why or Why not? Twenty-eight of the 36 teacher 
candidates who responded (45 in class total) described self-reflection activities as beneficial to their learning experience, and seven disagreed. The second question on the survey asked teacher candidates: Why do you think teacher candidates are asked to think about their own personal perspectives and understanding of First Nation, Métis, and Inuit histories, cultures, and perspectives in their preparation as a teacher? All of the 36 teacher candidates provided their perspective.

The following section discusses teacher candidates' survey responses in relation to the three defined categories. The survey responses are supported with examples from the seven teacher candidates' reflection papers, and in a few cases, observations noted in my reflective journal. A brief exploration of teacher candidates' critique of self-reflection activities concludes the findings section.

\section{A Process of Self-Evaluation}

Twenty-eight teacher candidates referenced self-evaluation in their response to the openended questions. From these responses, there emerged three types of self-evaluation statements, claiming that self-reflection raised awareness of personal knowledge or bias, provided an opportunity to expand knowledge and awareness, or aided in an exploration of the influences that have shaped knowledge and awareness (see Table 1).

Table 1

Self-reflection as a process for self-evaluation

\begin{tabular}{lcc}
\hline Type of self-evaluation & Number & $\%$ \\
\hline $\begin{array}{l}\text { Raised awareness of personal } \\
\text { knowledge }\end{array}$ & 12 & 42 \\
$\begin{array}{l}\text { Provided opportunity to } \\
\text { expand knowledge or } \\
\text { awareness }\end{array}$ & 9 & 32 \\
$\begin{array}{l}\text { Influences that have shaped } \\
\text { knowledge }\end{array}$ & 7 & 25 \\
\hline
\end{tabular}

Twelve teacher candidates wrote that self-reflection helped develop a self-awareness of knowledge or bias. In one example of this, a teacher candidate responded, "In order to develop in Aboriginal topics, one must be able to reflect on where they are starting and what their current knowledge is" (TC, 25). Another teacher candidate wrote, "It also allowed us to analyze our previous assumptions, knowledge, and schemas towards Aboriginal peoples and their history [and] culture," adding that self-reflection helps teacher candidates "to identify any hidden prejudice [and] stereotypes they may have formed, and to allow them to remove their bias from the classroom" (TC, 37).

While these statements acknowledged the importance of self-awareness, nine teacher candidates took this idea further and connected self-awareness with personal growth. One teacher candidate wrote, "In order to grow [and] expand our knowledge, we must first think about where we stand in our perspective" (TC, 31). In another response, a teacher candidate thought that the role of teacher candidates engaging in self-reflection was to "understand their 
base of knowledge and why they have more or less than their peers. Then they can build on that fact" (TC, 82).

Building on this notion of identifying and expanding personal knowledge, seven teacher candidates described reflective practices as an opportunity to examine how their knowledge, awareness, and biases were formed. These responses pointed to family, prior schooling, or personal experiences as influential sources. One teacher candidate wrote, "Past experiences and geography have a lot to do with people's knowledge and understanding" (TC, 43). The use of self-reflection to examine the roots of personal beliefs, assumptions, and biases were demonstrated in all eight reflection papers.

In one of the reflection papers, a teacher candidate associated her lack of knowledge about Indigenous peoples, cultures, and perspectives with her lack of contact with Indigenous peoples or communities. She wrote,

I am a first generation Canadian, I grew up in Canada but until three years ago, I did not know what Canadian meant. I had no idea that Indigenous people in Canada faced such hardships, and I had no idea that the crisis was ongoing....My experience with the Aboriginal community was very limited before I came to Lakehead University....We were ignorant to the presence of Indigenous peoples in Canada because we had never come into contact with them ourselves. $(\mathrm{RP}, 2)$

Though she believed that her awareness of Indigenous communities was limited, a position that Dion (2007) has described as the "perfect stranger." It was possible that the teacher candidate's exposure to Indigenous courses in University caused her to be more aware of the presence of Indigenous peoples, cultures, and perspectives in Canada. She further explained that through relationships with Indigenous people and academic courses, she has learned about historical traumas and the impact of trauma on Indigenous peoples and communities today.

In a different reflection paper, the teacher candidate shared an account of how quickly he formed a negative judgment against all First Nation people. He wrote that on his first day in Thunder Bay, Ontario, he witnessed a First Nation man being arrested for public intoxication. He described the impact it had on him, writing, "Within the course of three minutes, I had already passed judgment not on just one individual, but all of the First Nations [people] living in Thunder Bay" (RP, 1). In his reflection paper, he further unpacked his experience and began to articulate how long it took him to let go of this prejudice. He used self-reflection to acknowledge and evaluate what his personal beliefs and general attitude were towards First Nation peoples living in Thunder Bay. By engaging in a process of self-evaluation, he demonstrated selfawareness of his beliefs and prejudices, and an understanding of the importance of examining the roots of those beliefs and prejudices to change his attitude towards Indigenous peoples.

It was evident from the reflection papers and the open-ended question responses that the student was not alone in his realization that many beliefs and assumptions were in need of reexamination in order to identify hidden biases and prejudices. One teacher candidate wrote that the reflection paper "made me look back at my own beliefs and question them" (TC, 73). In another response, a teacher candidate wrote that self-reflection has helped: "To understand better why [teacher candidates] have the views they have and [be]come more aware of them" (TC, 79). One teacher candidate connected reflection with an examination of one's own social and cultural location, and responded: 
I think teachers are asked to think about their personal perspective in relation to First Nation, Métis, [and Inuit peoples] so they can consider their social location and the inherent privilege that is associated with majority groups, but most importantly, so teachers can relate First Nation, Métis, [and Inuit] culture[s] to their own culture. (TC, 80)

Our beliefs are shaped by our own social, political, or cultural experiences, and when left unexamined, they can become cemented in our minds as the "truth" with little understanding of the impact that this type of rigid mindset can cause in the classroom (Nuri-Robins et al., 2012). As was described, one experience of watching someone being arrested led to an unfair judgment against an entire First Nations community. Another teacher candidate shared her story of the impact that prior schooling had on her negative view of Indigenous classmates:

I believe my negative schooling experiences rooted my negative perspective towards Indigenous peoples . ... From what I witnessed in school, my teachers seemed to underestimate the abilities of Aboriginal children, almost brushing them off because they were considered 'unintelligent'.... Most of my teachers became easily frustrated with the students, and throughout the year basically disregarded them completely. (RP, 6)

Her reflection on previous school experiences helped her identify harmful pedagogical practices. This type of self-reflection was useful in determining what were and were not inclusive teaching practices, and has the potential to aid in identifying and modifying one's own biases that influence teacher-student interactions.

Experiences in school or home can have either negative or positive influences on teacher candidates' perspectives on Indigenous peoples, cultures, and histories. A teacher candidate who began the course with a keen interest to learn shared how her parents' interest to learn influenced her personally. She explained:

Both of my parents will often share with me their thoughts on different topics. Most recently my mom has been extremely engaged with the Truth and Reconciliation Commission Report. I have learned from my mom that Aboriginal people are still hurting, and that we all need to be a part of their healing. (RP, 7)

She expressed gratitude for the knowledge that her parents had provided but also acknowledged that more learning was needed: "I have so much more to learn as I am just beginning my learning journey." A willingness to learn as a teacher relates to positive teacher-student interactions in cross-cultural contexts (Oskineegish, 2015; Tompkins, 1998). Even so, numerous scholars warn that learning about other cultures can not be viewed as enough. Teachers must turn inward to examine how their perspectives or biases have influenced their teaching practices (Hammond, 2015; Nuri-Robins et al., 2012).

It can be shocking or uncomfortable to uncover deeply held prejudices, assumptions or biases. One teacher candidate wrote about her personal discovery in her reflection assignment: "I thought I was a very understanding person when it came to culture until I took classes at Lakehead [University] and found out that I still fed into absurd stereotype traps." She added, "Even though I was opened up to more diverse cultures as an adolescent, when I was young I grew up in a racist household" (RP, 5). Another teacher candidate provided this statement about 
unpacking prejudices and biases: "Sometimes you think you are really open and understanding, but then you realize you're kind of racist. And you shouldn't be a racist teacher" (TC, 32).

Self-reflection in the Aboriginal Education course provided teacher candidates with a method of self-evaluation. Through the process of self-reflection, teacher candidates identified their beliefs, judgements, assumptions, and attitudes towards Indigenous students, and in some cases, incorrect beliefs, or negative judgments were identified and corrected through selfexamination of prior experiences that initially shaped those beliefs and assumptions.

\section{A Connection Between Personal Experience and Theory}

Another type of response that emerged from the open-ended questions and reflection papers was a personal connection between prior experiences and course theory. This connection was largely evident in the reflection papers as this was part of the expectation for the course assignments. However, with 13 teacher candidates noting this in their survey responses and during class discussions, self-reflection was beneficial to at least one-quarter of teacher candidates by deepening their comprehension of course material through the inclusion of personal experience and understanding.

One teacher candidate responded that self-reflection activities "allowed me a chance to expand on and explain my thoughts" (TC, 75). Another wrote, "My reflection paper supported my learning because it gave me the opportunity to connect my personal ideas, thoughts and feelings to the required text readings," adding that "[self-reflection] brought the readings into perspective with real life" (TC, 38). As a benefit to learning, a teacher candidate wrote, "It made me critically read the paper because I needed to offer my perspective on it. It also made me want to read the paper instead of just skimming through it" (TC, 29). In a similar vein, another teacher candidate provided this description:

I found the reflection papers from this class to be extremely beneficial. They allowed us to personalize the information and speak on the context as we would to a class. Being able to reflect on our knowledge and add to it is so valuable to teacher candidates. (TC, 69)

The connection between personal experience and course theory was articulated by teacher candidates as a beneficial process for personal learning in the survey responses and inclass sharing circles. In response to one of the assigned readings, a teacher candidate wrote, "I feel like I can relate to this and the experiences I had growing up. I grew up holding a negative assumption about people, even though I thought I was a very accepting person" (RP, 5). She further shared that in high-school she had initially judged and ignored new Canadians in her class, but then changed her mind-set about helping classmates during class assignments; she explained, "I really wanted to help them because I thought about how hard it would be for me to go to another country that did not speak English and receive no help from my classmates, only judgments" (RP, 5).

In another reflection paper, a teacher candidate connected a common myth that she had heard with one of the assigned readings:

Another common judgment that is placed on Aboriginal people is that they are given everything for free without having to pay taxes. Through discussion with other people, it is evident that this is something that people see as a personal loss. People feel as if they 
are losing something only for Aboriginal people to gain. I connected this to the idea of interdependences in the article. Contrient interdependence involves people who think that one's gain will be another's loss. (RP, 7) assignments:

In another reflection paper, a teacher candidate explored the use of language in her

A particular struggle within this discipline is the prominent use of blanket terms when referring to Native peoples. I myself am guilty of doing this, even just within this paper, terms such as Indigenous; Aboriginal; Native; and Indian are meant to make reference to all peoples and communities of the original inhabitants of North America. These terms don't aim to make specific reference to communities and their cultural differences but rather generalize the population to differentiate them as 'Native Canadians' from what is considered 'Canadian'. (RP, 3)

These examples of personal connections to class theory highlighted various ways in which teacher candidates personalized readings and course theory while engaged in self-reflection. Self-reflection assisted some teacher candidates to think more deeply about what they were reading and to connect theory with their own personal beliefs and assumptions.

In my position of participant-as-observer, I noticed that many of the teacher candidates appeared to speak openly during the non-traditional sharing circles that were used in both sections of the Aboriginal Education course. Teacher candidates spoke about the positive and negative experiences that shaped their views of Indigenous education in connection to course readings. Through this method of sharing that also promoted self-reflection, some teacher candidates commented that they appreciated participating in the non-traditional sharing circles, because they felt heard and respected. It is important to note that the learning environment and the type of instructional strategies used can impact teacher candidates' willingness to engage in self-reflection activities throughout a course. In this course, the instructor's experience with sharing circles may have aided teacher candidates' willingness to reflect and share.

\section{Developing a Culturally Inclusive Pedagogy}

Seventeen teacher candidates referred to the development of a culturally inclusive pedagogy. In these responses, teacher candidates discussed the integration of Indigenous content, Indigenous students, or inclusive teaching practices in a multicultural classroom. In connection to integrating Indigenous content, one teacher candidate provided this response: "It's important for us to think about our perspectives because when we become teachers we will be in charge of teaching Aboriginal Education and how we incorporate it into the curriculum" (TC, 26).

Of equal concern were teacher-student interactions. In response to self-reflection activities, a teacher candidate wrote: "Social interactions shape how people see themselves. If a teacher has a negative perspective of Aboriginal people[s], it will affect how they interact with their students which can in turn affect their sense of identity" (TC, 44). From the 17 responses relating self-reflection to culture, eight directly discussed teaching Indigenous students or integrating Indigenous content. Nine teacher candidates referred to teaching in a multicultural classroom. In this context, a teacher candidate wrote: "As teachers, we must grasp the aspect of multiculturalism as it will be predominant later in the classroom. It is important to understand how to teach each child respectfully to their culture" (TC, 38). In response to the reflection 
paper, one teacher candidate wrote: "I found the reflection papers helpful for critically thinking about how I am going to help students with or without an Indigenous background. It caused me to rethink about what I should be doing to help students" (TC, 31). In these examples, selfreflection was described as a way to develop pedagogy in general, not just in Indigenous education.

Acknowledging culture in the classroom was discussed in a few of the reflection papers. In one teacher candidate's paper, she explored the inadequacy of integrating a lesson or two on cultures. She wrote:

It is the teacher's job to accommodate and allow students to feel welcome and comfortable. A lot of my teachers had a lesson or two about culture. In my food and nutrition class we cooked foods from various cultures; in my English class we read poems about cultures for one or two periods. Although this is a great start, I feel like that is all it is - a start. .... Culture to me is limited; there was so much to learn but it was only incorporated into a couple of lessons and never really expanded upon." $(\mathrm{RP}, 5)$

The overall role of reflection was described by teacher candidates as a process to examine and uncover false ideas or stereotypes of Indigenous peoples, cultures, or perspectives. The majority of the teacher candidates recognized the importance of looking inward when thinking about how to develop a culturally inclusive pedagogy, and, although it is unknown how this experience has influenced them in their teaching career. It can be a good start (Hammond, 2015; Nuri-Robins et al., 2012). Through informal discussions with teacher candidates in both sections of the course, it was clear that teacher candidates were split in their career goals. While some planned to remain in Northwestern Ontario, others planned on teaching in urban schools in southern Ontario, which are more culturally diverse. This information helped explain why so many of the teacher candidates referenced multiculturalism in a survey on Indigenous education.

\section{Challenges of Self-Reflection}

Though 28 of 35 teacher candidates appreciated self-reflection assignments in the course, seven teacher candidates stated that they did not find the assignments useful to their teacher preparation. These teacher candidates described some of the challenges that they encountered in completing the reflection papers, from unclear guidelines or expectations to a personal dislike of the paper's integration of assigned readings alongside personal discussion. One teacher candidate thought that the marking scheme did not align with the reflection paper's expectations, making this point: "Marking scheme seemed to value a commentary of the readings over identification of our pedagogy" (TC, 80). Another teacher candidate found the reflection paper's expectations confusing, and wrote: "I found them difficult to write, because I was not fully sure what was expected of me" (TC, 82).

With the emphasis on self-reflection, one teacher candidate was unsure how they would incorporate "what I learned in this class to what I will be teaching" (TC, 83). Every student responds to assignments differently. While one teacher candidate appreciated the catalyst to critically read course texts, another teacher candidate felt the combination of course readings and personal perspective caused them to lose focus in the reflection paper.

The teacher candidates who expressed dissatisfaction with the reflection paper assignment did not object to the use of self-reflection and provided a definition of the benefits of 
self-reflection in the Aboriginal Education course. Still, the challenges identified by some teacher candidates echoed the lack of clarity surrounding the purpose of self-reflection addressed in the literature (Russell, 2013). This suggests that instructors must recognize that not everyone will respond with the same eagerness to, or understanding of, self-reflection and its purpose in teacher preparation. Another possible reason that some teacher candidates may have been critical of self-reflection assignments may stem from a personal discomfort of conversations on privilege, oppression, or racism (Schick \& St. Denis, 2005). In this study, it is unclear if this was the case for teacher candidates in the Aboriginal Education course.

\section{Discussion}

The most frequent description of the role of self-reflection by teacher candidates was its use for self-evaluation. Teacher candidates participating in the study engaged in a process of selfevaluation of their own knowledge, awareness, or assumptions towards Indigenous peoples, cultures, and perspectives. This self-evaluation led some teacher candidates to conceptualize a direct connection between inclusive teaching practices and internal beliefs and assumptions. The use of comparisons and contrasts was evident in all eight reflection papers as each teacher candidate thought about how previous experiences had influenced their current knowledge or bias, and in some cases, promoted new ways of thinking about teaching that extended beyond their own experiences.

In describing self-reflection, 13 teacher candidates stated that it provided them with a process for creating a personal connection between their prior experiences and course theory. The personal connection was evidenced in various degrees in the reflection papers and during the non-traditional sharing circles. The process of drawing comparisons and contrasts occurred as teacher candidates tried to make sense of course theory through reflections on prior knowledge and experiences - a process that was also demonstrated with teacher candidates who used selfreflection to help in their development of a culturally inclusive pedagogy. Teacher candidates became mindful of beliefs and assumptions that they identified as a hindrance or assistance to their own ability to develop a culturally inclusive pedagogical practice and exemplified the practice of self-education that has been aligned with self-reflection (Schön, 1983; Tann, 1993).

In the written responses of the role of self-reflection, many of the teacher candidates provided more than one type of response. As previously mentioned, 22 teacher candidates identified more than one use of self-reflection, while two identified all three themes described in this paper, and 12 teacher candidates referenced only one of the themes. In the context of the Aboriginal Education course, many of the teacher candidates demonstrated, in part, some of the internal tasks described by Hammond. Whether teacher candidates continue to expand on these skills in their teaching practice is unknown. It is possible that some teacher candidates completed the self-reflection tasks simply to complete the course. Yet, the fairly large number of teacher candidates who indicated that self-reflection was beneficial to their learning, supports the need for further research on the impact of self-reflection on teacher candidates. Future research on how self-reflection and self-reflective practices impact teacher candidates entering their teaching career would provide further evidence of its effectiveness.

The findings in this study highlight teacher candidates' use of, and perspective on, selfreflection in an Indigenous education course. Teacher candidates formulated their own descriptions of the role of self-reflection that reiterated existing claims made about self-reflection 
in teacher education (Farrell, 2012; Rodgers, 2002; Tann, 1993), as well as the use of selfreflection in developing a culturally responsive approach to teaching (Gay, 2010; Hammond, 2015). The findings show that in an Indigenous education course, the use of self-reflection can provide teacher candidates with the tools to begin to uncover their beliefs, assumptions, and prejudices that impact their ability to integrate Indigenous content and develop inclusive teaching practices appropriately.

\section{Conclusion}

Preparing teacher candidates to be open to learning about integrating Indigenous histories, cultures, and perspectives in their curricula and building a pedagogical practice that is supportive of Indigenous students is very much needed in teacher education programs (Aveling, 2006; Mashford-Pringle \& Nardozi, 2013). Providing teacher candidates with courses, workshops, or seminars on Indigenous knowledges and pedagogies in a cross-cultural frame is necessary but not sufficient. It is critical that through this process of learning teacher candidates must recognize and be accountable in professional practice for their reactions to Indigenous-based theories and content.

In this study, self-reflection was employed in several ways: an open-ended survey on the role of reflection in the course; in class reflection assignments by a small subset of students, and my reflections as participant-as-observer in the course. Overall, self-reflection was considered to be effective in allowing participants the means to self evaluate their knowledge, beliefs, and assumptions about Indigenous and non-Indigenous people through a process of comparing and contrasting. Some found self-reflection aided their ability to make connections between course theory and their own experience that assisted in developing a culturally inclusive pedagogy.

The self-reflection activities in this study had an overall positive impact on teacher candidates, but more understanding of the process and experiences of teacher candidates is needed, such as how the differences in programming and course delivery affect the experiences and outcomes for participants ( 9 versus 12 weeks; 1-year versus an integrated program; rate and pace of course delivery; differences in course content; pedagogical strategies and exposures). A clear definition of what the purpose of reflection is and an outline of what is expected in selfreflection assignments with theoretical rational in the syllabus may lead to fewer misunderstandings for teacher candidates new, or resistant, to self-reflection. The findings in this paper illustrate the potential impact that the practice of self-reflection has on teacher candidates in teacher preparation programs that focused on Indigenous education. Since many of the students are non-Indigenous teacher candidates these findings contribute to research of the issues that arise with professional preparation of non-Indigenous teacher candidates to teach both nonIndigenous and Indigenous students by integrating Indigenous content and pedagogical approaches into the curriculum. 


\section{References}

Aveling, N. (2006). 'Hacking at our very roots': Rearticulating White racial identity within the context of teacher education. Race Ethnicity and Education, 9(3), 261-274. doi:10.1080 $/ 13613320600807576$

Blimkie, M., Vetter, D. M., \& Haig-Brown, C. (2014). Shifting perspectives and practices: Teacher candidates' experiences of an Aboriginal infusion in mainstream teacher education. Brock Education, 23(2), 47-66. doi:10.26522/brocked.v23i2.384

Cannon, M. (2012). Changing the subject in teacher education: Centering Indigenous, diasporic, and settler colonial relations. Cultural and Pedagogical Inquiry, 4(2), 21-37. doi:10.18733 /C3KS3D

Castagno, A. E., \& Brayboy, B. M. J. (2008). Culturally responsive schooling for Indigenous youth: A review of the literature. Review of Educational Research, 78(4), 941-993. doi:10.3102/0034654308323036

Cohen, A., \& Bai, H. (2012). Minding what really matters: Relationship as teacher. In C. Chambers, E. Hasebe-Ludt, A. Sinner, \& C. Leggo (Eds.), A heart of wisdom: Life writing as empathic inquiry (pp. 257-266). New York, NY: Peter Lang.

Creswell, J. W. (2010). Mapping the developing landscape of mixed methods research. In A. Tashakkori \& C. Teddlie (Eds.), Sage handbook of mixed methods in social and behavioral research, $2^{\text {nd }}$ ed. (pp. 45-68). Washington, DC: SAGE.

Curwen Doige, L. A. (2003). A missing link: Between traditional Aboriginal education and the Western system of education. Canadian Journal of Native Education, 25(2), 144-160.

Delpit, L. (2006). Other people's children: Cultural conflict in the classroom. New York, NY: Norton.

Demmert, W. G. Jr. (2011). What is culture-based education? Understanding pedagogy and curriculum. In J. Reyhner, W. S. Gilbert, \& L. Lockard (Eds.), Honoring our heritage: Culturally appropriate approaches for teaching Indigenous students (pp. 1-9). Flagstaff, AZ: Northern Arizona University.

DeWalt, K. M., \& DeWalt, B. R. (2002). Participant observation: A guide for fieldworkers. Walnut Creek, CA: AltaMira Press.

Dion, S. D. (2007). Disrupting molded images: Identities, responsibilities and relationships teacher and Indigenous subject material. Teaching Education, 18(4), 329-342. doi:10.1 080/10476210701687625

Dion, S. D. (2009). Braiding histories: Learning from Aboriginal peoples' experiences and perspectives. Vancouver, BC: UBC Press.

Farrell, T. S. C. (2012). Reflecting on reflective practice: (Re)visiting Dewey and Schön. TESOL Journal, 3(1), 7-16. doi:10.1002/tesj.10 
Garmon, M. A. (2004). Changing preservice teachers' attitudes/beliefs about cultural diversity: What are the critical factors? Journal of Teacher Education, 55(3), 201-213. doi: $10.1177 / 0022487104263080$

Gay, G. (2010). Culturally responsive teaching: Theory, research, and practice (2nd ed.). New York, NY: Teachers College Press.

Gay, G., \& Kirkland, K. (2003). Developing cultural critical consciousness and self-reflection in preservice teacher education. Theory Into Practice, 24(3), 181-187. doi:10.1207/s15430421tip4203_3

Grant, C., \& Sleeter, C. (2007). Doing multicultural education for achievement and equity. New York, NY: Routledge.

Hammond, Z. (2015). Culturally responsive teaching and the brain: Promoting authentic engagement and rigor among culturally and linguistically diverse students. Thousand Oaks, CA: Corwin.

Iseke-Barnes, J. (2008). Pedagogies for decolonizing. Canadian Journal of Native Education, 31(1), 123-148.

Johnson, R. B., Onwuegbuzie, A. J., \& Turner, L. A. (2007). Toward a definition of mixed methods research. Journal of Mixed Methods Research, 1(2), 112-133. doi:10.1177/1558689806298224

Keltchermans, G. (2009). Who I am in how I teach is the message: Self-understanding, vulnerability and reflection. Teachers and Teaching: Theory and Practice, 15(2), 257272. doi:10.1080/13540600902875332

Ladson-Billings, G. (1994). The dreamkeepers: Successful teaching for African-American students. San Francisco, CA: Jossey-Bass.

Lavallee, L. F. (2009). Practical application of an Indigenous research framework and two qualitative Indigenous research methods: Sharing circles and Anishnaabe symbol-based reflection. International Journal of Qualitative Methods, 8(1), 21-40. doi:10.1177/160940690900800103

Lewthwaite, B., Owen, T., Doiron, A., McMillan, B., \& Renaud, R. (2013). Our stories about teaching and learning: A pedagogy of consequence for Yukon First Nation settings. Interchange, 44, 105-128. doi:10.1007/s1080-013-9199-6

Mashford-Pringle, A., \& Nardozi, A. G. (2013). Aboriginal knowledge infusion in initial teacher education at the Ontario institute for studies in education at the University of Toronto. International Indigenous Policy Journal, 4(4), 1-19. doi:10.18584/iipj.2013. 4.4.3

Mason, S. (2007). The role of epiphanies in moral reflection and narrative thinking: Connectedness and good teaching. Interchange, 38(4), 351-366. doi:10.1007/s10780007-9036-X 
McDowall, A. (2017). (Not)Knowing: Walking the terrain of Indigenous education with preservice teachers. The Australian Journal of Indigenous Education, 1-9. doi:10.1017/jie.2017.10

McInnes, B. (2017). Preparing teachers as allies in Indigenous education: Benefits of an American Indian content and pedagogy course. Teaching Education, 28(2), 145-161. doi:10.1080/10476210.2016.1224831

Miller, J. R. (2003). Shingwauk's vision: A history of Native Residential schools. Toronto, ON: University of Toronto Press.

Milner, H. R. (2003). Teacher reflection and race in cultural contexts: History, meanings, and methods in teaching. Theory Into Practice, 42(3), 173-180. doi:10.1207/s 15430421tip 42032

Moll, L. C., Amanit, C., Neff, D., \& Gonzalez, N. (1992). Funds of knowledge for teaching: Using a qualitative approach to connect homes and classrooms. Theory into Practice, 31(2), 132-141. doi:10.1080/00405849209543534

Nabigon, H., Hagey, R., Webster, S., \& Mackay, R. (1999). The learning circle as a research method: The trickster and windigo in research. Native Social Work, 2(1), 113-117.

Nardozi, A., Restoule, J. P., Broad, K., Steele, N., \& James, U. (2014). Deepening knowledge to inspire action: Including Aboriginal perspectives in teaching practice. in education, 19(3), 108-122. Retrieved from http://ineducation.ca/ineducation/article/view/140/636

Nuri-Robins, K. J., Lindsey, D. B., Lindsey, R. B., \& Terrell, R. D. (2012). Cultural proficient instruction: A guide for people who teach $\left(3^{\text {rd }}\right.$ ed.). Thousand Oaks, CA: Cowin Press, SAGE.

Oskineegish, M., (2015). Are you providing an education that is worth caring about? Advice to non-Native teachers in northern First Nations communities. Canadian Journal of Education, 38(3), 1-25. Retrieved from https://files.eric.ed.gov/fulltext/EJ1073623.pdf

Oskineegish, M., \& Berger, P. (2013). The role of the non-Native teacher in remote First Nations communities in northern Ontario. Canadian Journal of Native Education, 36(1), 113-125.

Ottesen, E. (2007). Reflection in teacher education. Reflection Practice, 8(1), 31-46. doi:10.1080/14623940601138899

Regan, P. (2010). Unsettling the settler within: Indian Residential schools, truth telling, and reconciliation in Canada. Toronto, ON: UBC Press.

Rodgers, C. (2002). Defining reflection: Another look at John Dewey and reflective thinking. Teachers College Record, 104(4), 842-866.

Russell, T. (2013). Has reflective practice done more harm than good in teacher education? Phronesis, 2(1), 80-88. doi:10.7202/1015641ar

Sameshima, P. (2007). Seeing shadows in new light: A procatalepsis on narrative inquiry as professional development. (Special issue: Creativity and education: An international perspective), New Horizons in Education, 55(3), 10-21. 
Savin-Baden, M., \& Major, C. H. (2013). Qualitative research: The essential guide to theory and practice. New York, NY: Routledge.

Schick, C., \& St. Denis, V. (2005). Troubling national discourses in anti-racist curricular planning. Canadian Journal of Education, 28(3), 295-317. doi:10.2307/4126472

Schön, D. A. (1983). The reflective practitioner: How professionals think in action. New York, NY: Basic Books.

Scully, A. (2012). Decolonization, reinhabitation and reconciliation: Aboriginal and place-based education. Canadian Journal of Environmental Education, 17, 148-158. Retrieved from https://cjee.lakeheadu.ca/article/view/1113

Solomon, R. P., Portelli, J. P., Daniel, B., \& Campbell, A. (2005). The discourse of denial: How White teacher candidates construct race, racism and 'White privilege'. Race Ethnicity and Education, 8(2), 147-169. doi:10.1080/13613320500110519

Stock, R. V., Sameshima, P., \& Slingerland, D. (2016). Constructing pre-service teacher identities through processes of parallax. Special Issue: Artful inquiry: Transforming understanding through creative engagement. LEARNing Landscapes, 9(2), 489-512.

Tann, S. (1993). Eliciting student teachers' personal theories. In J. Calderhead \& P. Gates (Eds.), Conceptualising Reflection in Teacher Development (pp. 53-69). Washington, DC: The Falmer Press, Taylor \& Francis.

Tashakkori, A., \& Teddlie, C. (2010). Overview of contemporary issues in mixed methods research. In A. Tashakkori \& C. Teddlie (Eds.), Sage handbook of mixed methods in social and behavioral research, 2nd ed. (pp. 1-43). Washington, DC: SAGE.

The Truth and Reconciliation Commission of Canada [TRC]. (2012). Canada, Aboriginal peoples, and Residential schools: They came for the children. Retrieved from http://www.myrobust.com/websites/trcinstitution/File/2039 T\&R eng web[1].pdf

Tompkins, J. (1998). Teaching in a cold and windy place. Toronto, ON: University of Toronto Press.

Tupper, J. (2011). Disrupting ignorance and settler identities: The challenges of preparing beginning teachers for treaty education. in education, 17(3), 38-55. Retrieved from http://ineducation.ca/ineducation/article/view/71

Valli, L. (1993). Reflective teacher education programs: An analysis of case studies. In J. Calderhead \& P. Gates (Eds.), Conceptualising reflection in teacher development (pp. 1122). Bristol, PA: The Falmer Press.

Vetter, D. M., \& Blimkie, M. (2011). Learning to teach in culturally responsive and respectful ways: The first steps in creating a First Nation, Métis and Inuit education infusion in a mainstream teacher education program. The Canadian Journal of Native Studies, 31(2), 173-185. Retrieved from http://search.proquest.com/docview $/ 1020130053$ ?accountid=14771 
Villegas, A. M. (1988). School failure and cultural mismatch: Another view. Urban Review, 20(4), 253-265. doi:10.1007/BF01120137

Villegas, A. M., \& Lucas, T. (2002). Educating culturally responsive teachers: A coherent approach. Albany, NY: SUNY Press.

White, B., Sameshima, P., \& Sinner, A. (2015). Making identity: Perspectives on personal inquiry in teacher education. In S. Schonmann (Ed.), The wisdom of the many: Key issues in arts education, International Yearbook for Research in Arts Education (Vol. 3, pp. 395-399). Münster, GE: Waxmann.

Wolf, S. J. (2012). Critical citizenship, popular theatre, and the social imagination of pre-service teachers. In R. Mitchell, \& S. Moore (Eds.), Politics, participation, and power relations: Transdisciplinary approaches to critical citizenship in the classroom and community (pp. 35-49). Rotterdam, NL: Sense. 